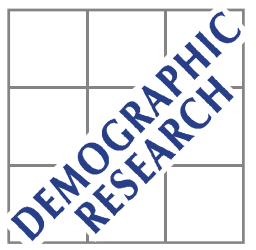

Demographic Research a free, expedited, online journal

of peer-reviewed research and commentary in the population sciences published by the Max Planck Institute for Demographic Research

Konrad-Zuse Str. 1, D-18057 Rostock · GERMANY

www.demographic-research.org

DEMOGRAPHIC RESEARCH

VOLUME 18, ARTICLE 19, PAGES 531-568

PUBLISHED 20 JUNE 2008

http://www.demographic-research.org/Volumes/Vol18/19/

DOI: 10.4054/DemRes.2008.18.19

Research Article

Does the recent evolution of Canadian mortality agree with the epidemiologic transition theory?

Marie-Hélène Lussier

Robert Bourbeau

Robert Choinière

(C) 2008 Lussier, Bourbeau \& Choinière.

This open-access work is published under the terms of the Creative Commons Attribution NonCommercial License 2.0 Germany, which permits use, reproduction \& distribution in any medium for non-commercial purposes, provided the original author(s) and source are given credit.

See http:// creativecommons.org/licenses/by-nc/2.0/de/ 


\section{Table of Contents}

1 Introduction 532

1.1 Social context in Canada 532

1.2 The epidemiologic transition theory: 532

Variants on the number of stages and their characteristics

1.3 The empirical work in Canada 534

1.4 Research questions 535

$2 \quad$ Data and methods $\quad 536$

$2.1 \quad$ Period of study and data 536

2.2 Definitions 536

2.3 Causes of death and compatibility in the long-term: The 537 international classification of diseases and its revisions

$3 \quad$ Results 538

3.1 The third phase of the epidemiologic transition in Canada 538

3.2 The sequel to the third stage in Canada 540

3.2.1 Was mortality's decline concentrated mostly in advanced ages and 541 did the decline occur at nearly the same pace for males and females? (Olshansky and Ault 1986)

3.2.2 Did the pattern of mortality by cause become stable (Olshansky and 543 Ault, 1986)?

3.2.3 Did specific changes occur within chronic diseases groups? 548

3.2.4 Did a gradual shift towards older ages take place in mortality by 550

3.2.5 Did mortality by social pathologies decline? (Rogers and 553 Hackenberg 1987)

3.2.6 Was the impact of AIDS on mortality significant? Did a resurgence 555 of infectious diseases like cholera, diphtheria and dengue take place? (Omran 1998)

3.2.7 Did mortality due to pneumonia and influenza increase? (Olshansky et al. 1998)

4 Discussion 558

5 Conclusion $\quad 561$

6 Acknowledgments 562

References 563 


\title{
Does the recent evolution of Canadian mortality agree with the epidemiologic transition theory?
}

\author{
Marie-Hélène Lussier ${ }^{1}$ \\ Robert Bourbeau ${ }^{2}$ \\ Robert Choinière ${ }^{3}$
}

\begin{abstract}
After studying the epidemiologic transition's situation in Canada, it is determined that the delimitation of temporal stages within the epidemiologic transition as put forward by Omran (1971, 1998), Olshansky and Ault (1986), Rogers and Hackenberg (1987) and Olshansky et al. (1998) does not suit the Canadian evolution. Many of the researchers' postulates on the epidemiologic transition were not confirmed, which leads us to assert that, since 1958, the epidemiologic transition in Canada is best described as an evolution process rather than specific stages confined within time limits.
\end{abstract}

\footnotetext{
${ }^{1}$ Colorado Department of Health Care Policy and Financing, USA. E-mail: mhlussier@hotmail.com.

${ }^{2}$ Department of Demography, Université de Montréal. E-mail: robert.bourbeau@umontreal.ca.

${ }^{3}$ Institut National de santé publique du Québec. E-mail: robert.choiniere@ inspq.qc.ca.
} 


\section{Introduction}

The last century has been the witness to numerous changes in population evolution, including an important decline in fertility, paired with a regression of mortality due in part to the changing nature of causes of death. The study of the theory of the epidemiologic transition has allowed better insight of the processes behind the evolution of mortality and causes of death in developed countries. However, this theory of the epidemiologic transition has also been a controversial issue among researchers in the last few decades. The object of this analysis is to study the evolution of the late stages of the epidemiologic transition in Canada, and to determine where Canada stands among the theoretical stages of the epidemiologic transition suggested by various researchers.

\subsection{Social context in Canada}

Various socio-economic indicators like the Gross Domestic Product (GDP) and human development index rank Canada as one of the wealthiest and most developed nations in the world. Canada has also one of the highest life expectancies at 80.2 years old for combined sexes in 2004, which is 2.4 years higher than the United States'. Canada has a publicly funded health care system where the government contributes $70 \%$ of total health care costs. As a comparison, public funds cover $45 \%$ of health care expenses in the United States (OECD 2007). Moreover, immigrants make up a significant portion of the population as $19.8 \%$ of Canadian residents are foreign-born, which is over $7 \%$ higher than the official figure for the United States (Chui, Tran, and Maheux 2006). The large immigrant population bolsters Canada's health indicators because immigrants are admitted into Canada upon their health status. This is typically referred to as the "healthy immigrant effect".

\subsection{The epidemiologic transition theory: Variants on the number of stages and their characteristics}

In 1971, following the incomparable decline of mortality in developed countries, Omran put forward a theory describing for the first time the decrease of infectious diseases, gradually replaced by chronic diseases. It was labelled the "epidemiologic transition" and was initially comprised of three phases spread throughout the last few centuries describing this shift between the main causes of death. According to Omran, the first phase, called the "age of pestilence and famine" lasted until the middle of the $19^{\text {th }}$ century and was characterized by high and fluctuating mortality due mostly to 
infectious diseases. The second phase (the "age of receding pandemics") ended in the middle of the $20^{\text {th }}$ century for most developed countries and is distinguished by the onset of the shift from infectious to chronic diseases, and the increase of life expectancy. The third phase, identified as the "age of degenerative diseases", is characterized by the predominance of chronic diseases and the stabilization of mortality at a low level.

In the mid-1980s, a fourth stage of the epidemiologic transition was suggested when researchers found that, contrary to what Omran had predicted, the decline of mortality never stopped (Olshansky and Ault 1986; Rogers and Hackenberg 1987). Subsequently, other researchers put forward variants or additions to the third stage of Omran and to the fourth stage of Olshansky and Ault (Olshansky et al. 1998; Omran 1998; Robine 2001; Meslé and Vallin 2002).

More specifically, Olshansky and Ault (1986) were the first to propose a fourth stage after observing an uninterrupted increase in life expectancy. They believed this trend was important enough to distinguish it from Omran's three previous phases. The fourth stage suggested by Olshansky and Ault can be summarized by three general characteristics:

i. Rapidly declining death rates concentrated mostly in advanced ages and occurring at nearly the same pace for males and females;

ii. A relatively unchanged age pattern of mortality by cause, but a progressive shift towards older ages of the age distribution of deaths by degenerative causes; and

iii. Relatively rapid movements in survival concentrated among the population in advanced ages.

This fourth stage is referred to as the "age of delayed degenerative diseases". When Olshansky and Ault published their article in 1986, they argued that the USA had already entered the fourth stage of the epidemiologic transition, although a time-frame was not specified.

In 1998, Omran recognized the existence of one and possibly two additional stages to his initial theory of the epidemiologic transition. According to Omran, the fourth stage is characterized by an ongoing rise in life expectancy until it reaches 80 to 85 years old; by a stabilization, then a decrease, of cardiovascular diseases as a cause of death; as well as by the emergence of new diseases (HIV; hepatitis B and C; Ebola; Lyme disease; Hantaan virus; new forms of E.Coli, etc.) and by the revival of former diseases (cholera; malaria; dengue; diphtheria; tuberculosis; plague; and Chagas disease). 
Rogers and Hackenberg (1987) also proposed a fourth stage of the epidemiologic transition. They agreed with Olshansky and Ault that degenerative diseases remain the leading cause of death, but their main argument against Omran's original theory is the fact that the evolution of violent deaths (or deaths due to social pathologies: mainly accidents, suicides, and homicides) were not included in his theory.

Robine (2001) has been even harsher than the previous researchers in his critique of the theory of the epidemiologic transition. Particularly, Robine has doubted the very existence of the last two stages (Omran's stage of degenerative diseases and Olshansky and Ault's stage of delayed degenerative diseases) after studying the evolution of dispersion of life spans.

For Meslé and Vallin (2002), the epidemiologic transition is comprised of two stages, and perhaps a third. They have acknowledged Omran's first stage during which the improvement in survival is due mostly to the collapse of infectious diseases and to the rise of chronic diseases. They believe that the second and last stage takes place when the growth of life expectancy starts being sustained almost entirely by the decline of cardiovascular diseases. They have referred to this stage as the "cardiovascular revolution". They have also suggested that by pushing back life expectancy incessantly, women of the most developed countries might have entered a third stage, described as the "fight against ageing" (Vallin and Meslé 2004).

A variety of other researchers have also published their analysis of the existence, evolution or attributes of the epidemiologic transition (Meslé 1997; Fetter 1997; Rogers and Nelson 1997; Mackenbach 1994; Caselli and Egidi 1991; Burgio and Frova 1995). Since this theory has been fuelling debate over the last few decades, we deemed it pertinent to clarify the status of the epidemiologic transition in Canada.

\subsection{The empirical work in Canada}

A few Canadian studies have attempted to determine whether Canada has experienced the theoretical assertions of the epidemiologic transition's late stages.

Nagnur and Nagrodski's analyses $(1987 ; 1990)$ showed that the evolution of the epidemiologic transition described by Omran could be observed for Canada between 1931 and 1981, but they did not venture on the status of the fourth stage, or provide temporal indications on the switch from the second to the third stage or from the third to the fourth. However, Bah and Rajulton (1991) claimed that Nagnur and Nagrodski's research $(1987 ; 1990)$ showed that Canada reached the third stage of the epidemiologic transition in the 1950s, even though Nagnur and Nagrodski themselves did not explicitly give any estimation on that matter. The ambiguity of these statements has prompted us to clarify the Canadian situation. 


\subsection{Research questions}

Before discussing the core of our research analysis, we will establish more precisely when Canada made the transition from Omran's second to third phase. Because there is no consensus among researchers on what happens beyond Omran's third stage, our research objectives focus primarily on that matter. The following questions are inspired by the allegations brought up by researchers:

1. Was mortality's decline concentrated mostly in advanced ages and did the decline occur at nearly the same pace for males and females? (Olshansky and Ault 1986)

2. Did the pattern of mortality by cause become stable (Olshansky and Ault 1986)?

3. Did specific changes occur within chronic disease groups?

4. Did a gradual shift towards older ages take place in mortality by chronic diseases? (Olshansky and Ault 1986)

5. Did mortality by social pathologies decline? (Rogers and Hackenberg 1987)

6. Was the impact of AIDS on mortality significant? Did a resurgence of infectious diseases like cholera, diphtheria and dengue take place? ${ }^{4}$ (Omran 1998)

7. Did mortality due to pneumonia and influenza increase? (Olshansky et al. 1998)

All questions arise from researchers who have worked on the epidemiologic transition except the third, relating to possible changes taking place within chronic diseases. Because the evolution of cardiovascular mortality is fully examined by questions 2 and 3, Meslé and Vallin's proposal (2002) on the cardiovascular revolution has not been included. Meslé and Vallin's suggestion is referred to in the conclusion.

After assessing each of the research questions, we will be better positioned to provide a verdict on the status of the epidemiologic transition in Canada.

\footnotetext{
${ }^{4}$ Cholera, diphtheria and dengue are three of the infectious diseases identified by Omran (1998) as having a comeback. We chose these three diseases over others for two reasons: the compatibility between ICD-7, ICDA-8 and ICD-9 are the least complex for these three diseases; in addition, diphtheria and dengue are two of the four infectious diseases that Olshansky et al. (1998) believe are resurfacing in North America.
} 


\section{Data and methods}

\subsection{Period of study and data}

The analysis starts in 1958, which is the first year of the $7^{\text {th }}$ revision of the International Classification of Diseases (ICD) in Canada, and which falls shortly before the slowing down of the decline of mortality observed in the 1960s (Bourbeau and Smuga 2003; Chasteland and Chesnais 1997). The final year of the analysis is 1999, which is the last year of the $9^{\text {th }}$ revision of the ICD in Canada. In fact, the largest difficulty met in this research was the revision changes of the ICD.

Statistics Canada provided the data on causes of death. The data was available by 5 -year age groups $(0-1,1-4,5-9,10-14, \ldots, 100+)$, by sex, and the causes of death were classified by 4-digit rubrics. The under-estimation of deaths is very low considering the requirement of death registering, and is mainly due to a delay of registration rather than an omission.

\subsection{Definitions}

When Omran described his epidemiologic transition theory, he used the term "degenerative diseases" without describing which diseases that term encompasses. Researchers working on the epidemiologic transition subsequently adopted "degenerative diseases" without questioning its definition. Later, the expression "chronic diseases" became increasingly used to define the most prevalent diseases within the population.

The term "chronic diseases" will be used in this analysis because it is more widespread in the literature, and has a universal and renowned definition in dictionaries, encyclopaedias and medical literature as well as among researchers working in the public health field. For this analysis, chronic diseases include six disease groups unanimously identified as such by numerous sources: malignant tumours (cancer or neoplasm); cardiovascular diseases; diabetes; chronic obstructive pulmonary diseases $\left(\mathrm{COPD}^{5}\right)$; osteo-articular, muscular and conjunctive tissue diseases (which include osteoporosis and arthritis); and Alzheimer's disease (Wolleswinkel-Van Den Bosch, J.H. et al. 1996; Santé Canada 2004; Ministère de la Santé et des Services Sociaux du Québec 2005; Center for Diseases Control and Prevention 2007; Brownson, R.C. et al. 1993; Trowell, H.C. and Burkitt, D.P. 1981). Therefore, when discussing "chronic diseases" without further detail, we will be referring to these six groups of diseases.

${ }^{5}$ COPD examined: emphysema, asthma and chronic bronchitis. 
Suicides, homicides and accidents comprise the main causes of death of Rogers and Hackenberg's "social pathologies".

\subsection{Causes of death and compatibility in the long-term: The international classification of diseases and its revisions}

Two steps must be taken with great circumspection in the study of the epidemiologic transition: the choice of causes of death to be analyzed and their follow-up in the longterm.

We converted the causes of death of the $7^{\text {th }}, 8^{\text {th }}$ and $9^{\text {th }}$ revisions of the International Classification of Diseases (ICD-7, ICDA-8 and ICD-9) to make them compatible. For major ICD revisions, Statistics Canada and the World Health Organisation (WHO) provide some basic documents to help make the transition between the old and new revision. Many other countries are faced with the same problem, namely the scarcity of manuscripts that detail the change of revisions (Wolleswinkel-Van Den Bosch et al. 1996). Since a complete cross-walk of codes is not available, the reclassification needs to be completed a posteriori (Vallin and Meslé 1996).

Moreover, Statistics Canada and various researchers have warned that tackling the discontinuity of ICD's sequences can be complex and needs to be approached with caution (Statistique Canada 1984; Meslé 1997). Fortunately, Vallin and Meslé have published a document establishing the compatibility of the statistical series between ICD-7 and ICDA-8; but their work is still in progress for the changes introduced by ICD-9 (Vallin and Meslé 1996). We have used their model to ensure the compatibility of our causes of death between the $7^{\text {th }}$ and $8^{\text {th }}$ revision of the ICD, but no work as exhaustive as Vallin and Meslé's (1987) has been published for the reconstruction of sequences between ICDA-8 and ICD-9. However, we have created a fairly accurate match between ICDA-8 and ICD-9 with the help of an article (Vallin and Meslé 1996) and a non-published report from Statistics Canada.

Making sure the causes of death used in this research paper were compatible through the three revisions of the International Classification of Diseases, and converting all the data into the $9^{\text {th }}$ revision standards, was a delicate process. The compatibility between the causes of death through time might not be perfect, but we believe that the work has been done with as much thoroughness as necessary. 


\section{Results}

\subsection{The third phase of the epidemiologic transition in Canada}

The shift from the second to the third stage in Canada did not arouse much interest from researchers. Most had assumed that this transition was completed by the middle of the $20^{\text {th }}$ century. Since our research questions relate to what happens after the third stage, it is essential to determine with more precision when the change from the second to the third stage took place.

We used two of Omran's main attributes describing the third stage: the predominance of mortality by chronic diseases, and the stabilization of mortality at a low level. Since Omran did not state exactly what he implied by predominance, we assumed in the context of this study that the predominance started when chronic diseases cause $50 \%$ or more deaths. The stabilization of mortality at a relatively low level is analyzed with standardized mortality rates.

The time frame examined to determine the period during which chronic diseases started their preponderance is 1921 until 1999, thus covering ICD-3 to ICD-9. Eight categories of chronic diseases were selected for this time frame: cancer; diabetes; cerebral haemorrhage, embolism and thrombosis (from 1921 to 1968); circulatory system diseases; chronic bronchitis; asthma; pulmonary emphysema; and bone and movement organ diseases. We understand that the compatibility of chronic diseases between ICD-3 and ICD-9 is imperfect, but is adequate since the objective of this section is solely to identify the approximate period of transition between the second and third stages. 
Figure 1: Percent of deaths due to chronic diseases by sex, Canada, 1921-1999

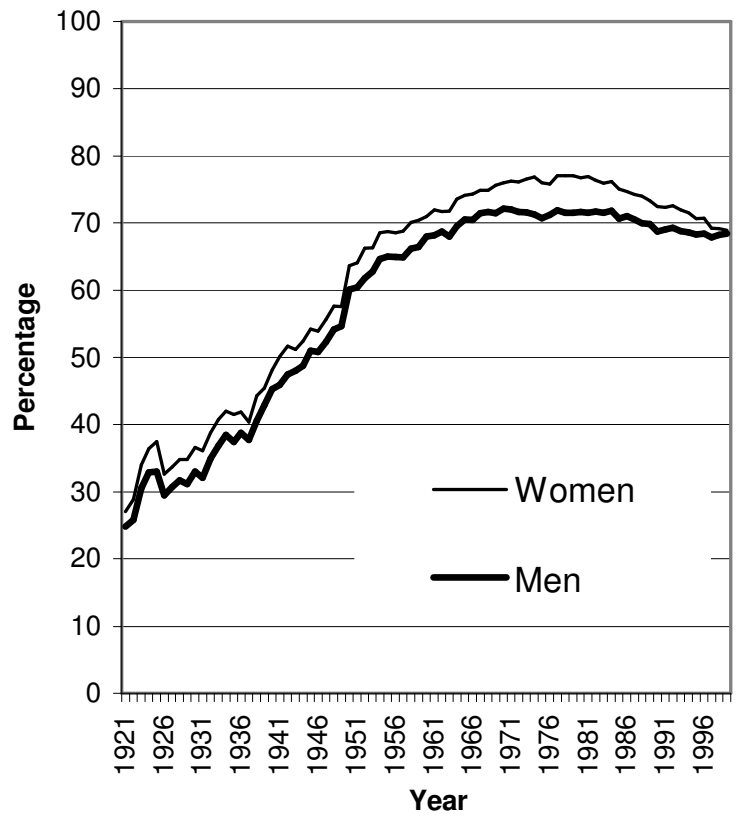

Sources: Dominion Bureau of Statistics, 1923-1947. Bureau fédéral de la statistique, 1948-1969. Statistique Canada, Catalogues 84206 (1970-1986), 84-204 (1978-1986), 82-003S (1987-1989), 82-003S15 (1989-1990), 82-003S11 (1990), 84-208 (1991-1993), 84-211 (1991-1992), 84-210-XPB (1993-1995), 84-208-XPB (1994-1995), 84-209-XPB (1995-1999), 84F0210XPB (1996-1997), 84F0208 (1996-1999), 84F0211XPB (1998-1999).

Figure 1 shows that chronic diseases began to cause half of female deaths in 1941; the men's trend followed four years later. Therefore, this first aspect of the third stage of the epidemiologic transition started towards the middle of the 1940s in Canada.

As far as Omran's second criteria, figure 2 reveals that mortality never completely stabilized. Until the middle of the 1940s, standardized rates ${ }^{6}$ evolved erratically, but the overall trend was definitely declining. The drop has been steady during the last 50 years. There have been short interruptions in the reduction of mortality, but they have not been long enough to classify as stagnation.

\footnotetext{
${ }^{6}$ We used the direct standardization method and employed the Canadian population in 1996 as the reference population. We obtained the expected deaths by multiplying age-specific mortality rates of each year by the same age-specific reference population.
} 
Figure 2: Standardized mortality rates by sex, Canada, 1921-1999

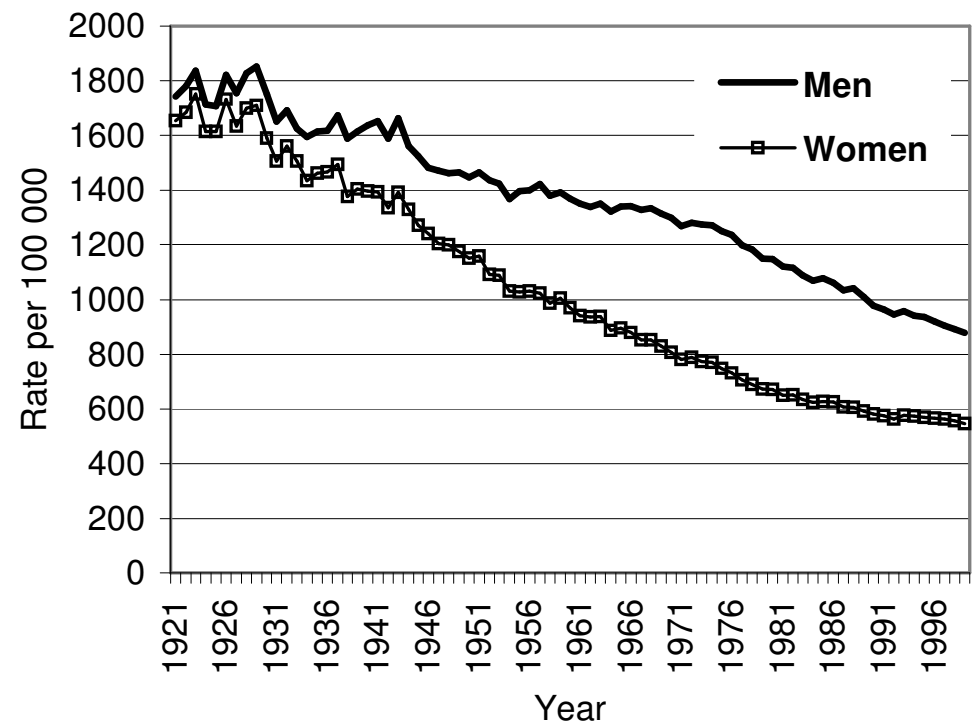

Sources: Same as figure 1.

Overall, we can assert that one of the two criteria describing the switch from the second to the third stage took place, which is the one regarding the predominance of chronic diseases. The stabilization of mortality criterion did not occur. There was indeed a slowing down of the decrease of mortality during the 1950s and 1960s, but the decline never completely stopped. The invalidation of Omran's second criterion compels us to reject the third stage as he had initially suggested it, in the case of Canada. Nevertheless, the mere fact that chronic diseases emerged so clearly indicates the beginning of a third stage of the epidemiologic transition which, although not the one suggested by Omran.

\subsection{The sequel to the third stage in Canada}

The purpose of this study is to clarify the evolution of the epidemiologic transition since the beginning of the third stage in Canada. Since only one of Omran's two criteria describing the third stage can be observed for Canada, the main focus is on further development since the epidemiologic transition seems to extend beyond the beginning 
of the third stage. Although we understand that the results depend on the indicators selected, we believe that if no ambiguity is associated with the results, all possible indicators would have probably come to equivalent conclusions.

\subsubsection{Was mortality's decline concentrated mostly in advanced ages and did the decline occur at nearly the same pace for males and females? (Olshansky and Ault 1986)}

The first sign of the delay of the degenerative diseases stage, suggested by Olshansky and Ault in 1986, is a decrease of mortality, which occurs primarily among the elderly and at the same pace for men and women. In breaking down life expectancy by age groups, a decline of mortality can be estimated, and the age groups that have contributed the most to the gain of life expectancy at birth between 1958 and 1999 can be evaluated as well.

As expected, the decline of mortality is confirmed throughout the entire period by a continuously growing life expectancy (table 1). Table 1 was calculated using the Arriaga method (Arriaga 1984). The Arriaga method calculates the contribution of different age groups to the increase in life expectancy at birth. ${ }^{7}$ Results differ greatly between men and women during the period 1958-1979. The growth of the male life expectancy between 1958 and 1979 is much more attributable to the decline of infant mortality than to the decrease of mortality among older ages. But this is not the case for women. Even though the decline of mortality at young ages was not negligible in the increase of female life expectancy between 1958 and 1979, the input of the older age groups to their life expectancy growth proved to be more significant.

\footnotetext{
${ }^{7}$ The Arriaga method is a way to decompose life expectancy between two periods to see which age groups contribute the most to the variation of life expectancy. It is calculated from life tables, and it estimates from lx, Lx and Tx, which age groups contributed the most to the gain or loss of life expectancy between periods.
} 
Table 1: Contribution of age groups (in years and in percent) to the increase in life expectancy at birth, men and women, Canada, 1958-1979 and 1979-1999

\begin{tabular}{|c|c|c|c|c|c|c|c|c|}
\hline \multirow[t]{3}{*}{ Age groups } & \multicolumn{4}{|c|}{$1958-1979$} & \multicolumn{4}{|c|}{$1979-1999$} \\
\hline & \multicolumn{2}{|c|}{ Men } & \multicolumn{2}{|c|}{ Women } & \multicolumn{2}{|c|}{ Men } & \multicolumn{2}{|c|}{ Women } \\
\hline & Gain & $\%$ & Gain & $\%$ & Gain & $\%$ & Gain & $\%$ \\
\hline $0-1$ year & 1.6 & $47.5^{8}$ & 1.4 & 28.5 & 0.5 & 10.5 & 0.4 & 13.1 \\
\hline 1-14 years & 0.3 & 9.9 & 0.3 & 5.5 & 0.3 & 5.1 & 0.2 & 6.3 \\
\hline $15-34$ years & 0.0 & -1.0 & 0.1 & 2.3 & 0.6 & 13.2 & 0.2 & 7.8 \\
\hline 35-64 years & 0.8 & 24.8 & 1.0 & 19.5 & 2.1 & 43.1 & 1.0 & 33.8 \\
\hline 65 years + & 0.6 & 18.8 & 2.2 & 44.2 & 1.4 & 28.2 & 1.2 & 39.1 \\
\hline Iotal & 3.4 & 100.0 & 4.9 & 100.0 & 4.9 & 100.0 & 3.1 & 100.0 \\
\hline
\end{tabular}

Source: Canadian Human Mortality Database, 2004.

Between 1979 and 1999, women aged 65 years and over contributed to a lesser degree in the increase of life expectancy than the previous period, but the growth remained the highest amongst this age group. As for men, their situation evolved significantly during the second time frame. The input of older age groups escalated compared to the prior period, but was once again exceeded by the adult age group (3464 years), which showed the most significant mortality decrease.

Since the results regarding the preponderant contribution of the elderly to the improvement of survival are not completely conclusive, we decided to examine what the outcome would be for the most recent period, 1990-1999. The results suggest that $35 \%$ of men's life expectancy increase recorded between 1990 and 1999 is attributable to greater survival among people aged 65 years and over. For the same period, the improvement of survival among elderly females compared to the other age groups was even greater since their input on the growth of life expectancy stood at $45 \%$.

The second part of the hypothesis, the decline of mortality occurring at the same pace for men and women, can be partly assessed by figure 1. During the first half of the period, the decrease of female mortality is more pronounced. Nevertheless, between

\footnotetext{
${ }^{8}$ The infant mortality rate among Canadian men dropped from 3,602 per 100,000 in 1958 to 1,253 per 100,000 in 1979 . This decline of almost $200 \%$ was the most important age-specific mortality rate decrease in men in this time period. The many young lives saved between 1958 and 1979 contributed the most to the surge in male life expectancy.
} 
the middle of the 1970s and 1999, the decline of mortality among men accelerates and that of women's slows, which brings the two mortality curves closer together. These trends are confirmed by table 2, which shows the variations of standardized mortality rates and of life expectancy at birth during the periods 1958-1999, 1958-1979 and 19791999. Both indicators reveal that the reduction of mortality is favourable to women between 1958 and 1979 and to men from 1979 to 1999.

Table 2: Variation of life expectancy at birth (increase in years) and of standardized mortality rates decrease (in percent) by sex, Canada, 1958-1999, 1958-1979, 1979-1999

\begin{tabular}{|c|c|c|c|c|c|c|}
\hline \multirow[t]{2}{*}{ Variations in: } & \multicolumn{2}{|c|}{ 1958-1999 } & \multicolumn{2}{|c|}{$1958-1979$} & \multicolumn{2}{|c|}{ 1979-1999 } \\
\hline & Men & Women & Men & Women & Men & Women \\
\hline $\begin{array}{l}\text { Life } \\
\text { expectancy } \\
\text { (years) }\end{array}$ & 8.4 & 8.0 & 3.4 & 4.9 & 5.0 & 3.1 \\
\hline $\begin{array}{l}\text { Standardized } \\
\text { mortality rates } \\
(\%)\end{array}$ & 36.4 & 44.7 & 16.8 & 32.0 & 23.6 & 18.7 \\
\hline
\end{tabular}

Sources: Canadian Human Mortality Database, 2004; Statistics Canada, Cat. 91-209F, 2002.

\subsubsection{Did the pattern of mortality by cause become stable (Olshansky and Ault, 1986)?}

One of the conditions to Olshansky and Ault's fourth stage is that the pattern of mortality by cause stays unchanged, but that the age distribution of deaths due to chronic diseases is progressively shifted toward older ages.

\section{Distribution of deaths by cause}

The proportions of causes of death through time are analyzed in order to estimate whether the pattern of causes of death remained roughly the same. Figure 3 reveals that, between 1958 and 1999, the main alteration was the gradual reduction of the supremacy of cardiovascular diseases (CVD), which were mostly replaced by the increasing prevalence of cancer. The weight of "other diseases" among the totality of causes of death lessened, as well as that of traumas (mainly accidents, suicides and homicides) 
which, however, recorded an increase of their importance in mid-period before starting their descent. After completely disappearing in the early 1980s, infectious and parasitic diseases (IPD) resurfaced following the emergence of AIDS. Similarly, the importance of respiratory diseases slightly intensified, as well as that of diabetes and Alzheimer's disease. Alzheimer's disease, however, was not acknowledged until the introduction of ICD-9. The significance of digestive system diseases among all causes of death was quite stable throughout the entire period.

\section{Figure 3: Distribution of deaths (in \%) by the cause, Canada, 1958-1999}

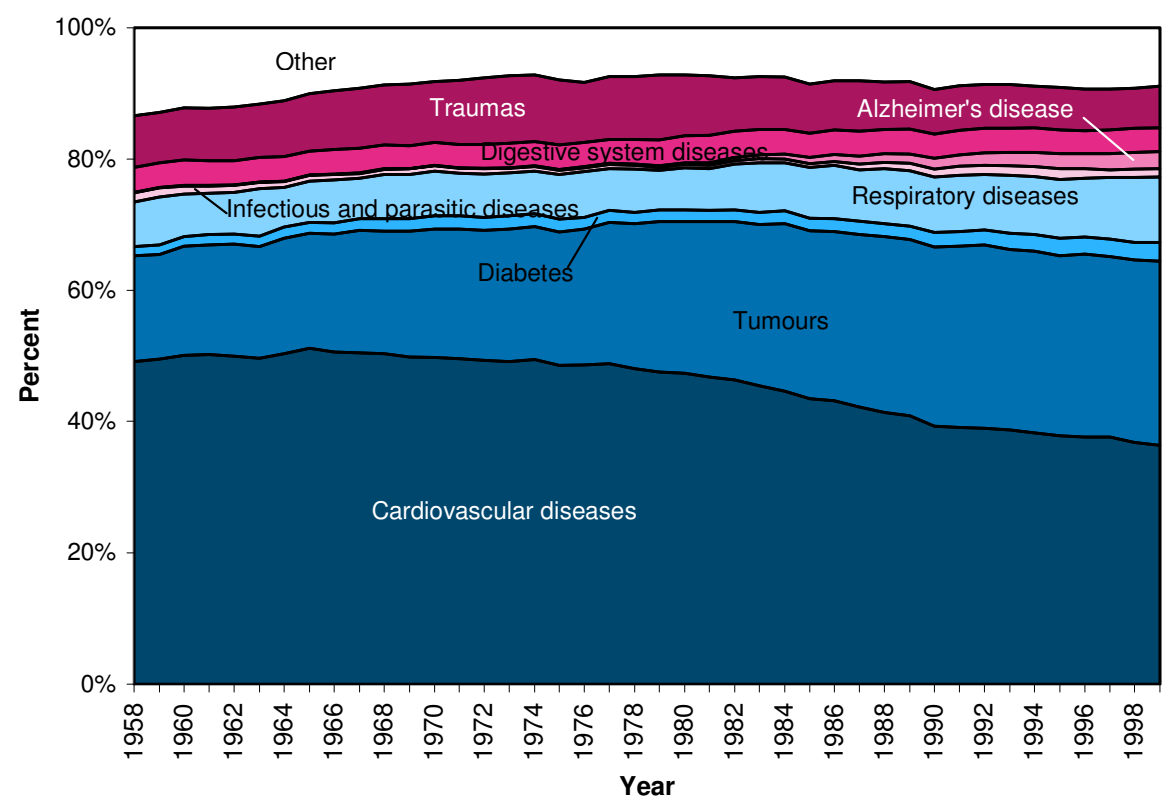

Sources: Bureau fédéral de la statistique, 1958-1969. Statistique Canada, Catalogues 84-206 (1970-1986), 84-204 (1978-1986), 82003S (1987-1989), 82-003S15 (1989-1990), 82-003S11 (1990), 84-208 (1991-1993), 84-211 (1991-1992), 84-210-XPB (19931995), 84-208-XPB (1994-1995), 84-209-XPB (1995-1999), 84F0210XPB (1996-1997), 84F0208 (1996-1999), 84F0211XPB (1998-1999).

\section{Standardized mortality rates by cause}

The standardized mortality rates by cause are examined in order to extend the analysis of the pattern of causes of death. Mortality rates were split into two figures representing 
standardized mortality rates for the broad causes of death in figure 3 , to ensure a clearer reading of the trends.

The steady decline of mortality by cardiovascular diseases in figure 4 is striking. The probability of dying from a cardiovascular disease has decreased significantly: the mortality rate dropped from 670 per 100000 in 1958 to 250 per 100000 in 1999 . Mortality rates by cancer have actually risen slightly despite the reduction of overall mortality since 1958. The combination of these two trends caused the two mortality curves to border each other by the end of the period, which would have been considered highly impossible in the late 1950s since the standardized mortality rate of CVD at that time was 3.5 times that of tumours.

Figure 4: Standardized mortality rates by cardiovascular diseases (CVD) and malignant tumours, both sexes, Canada, 1958-1999

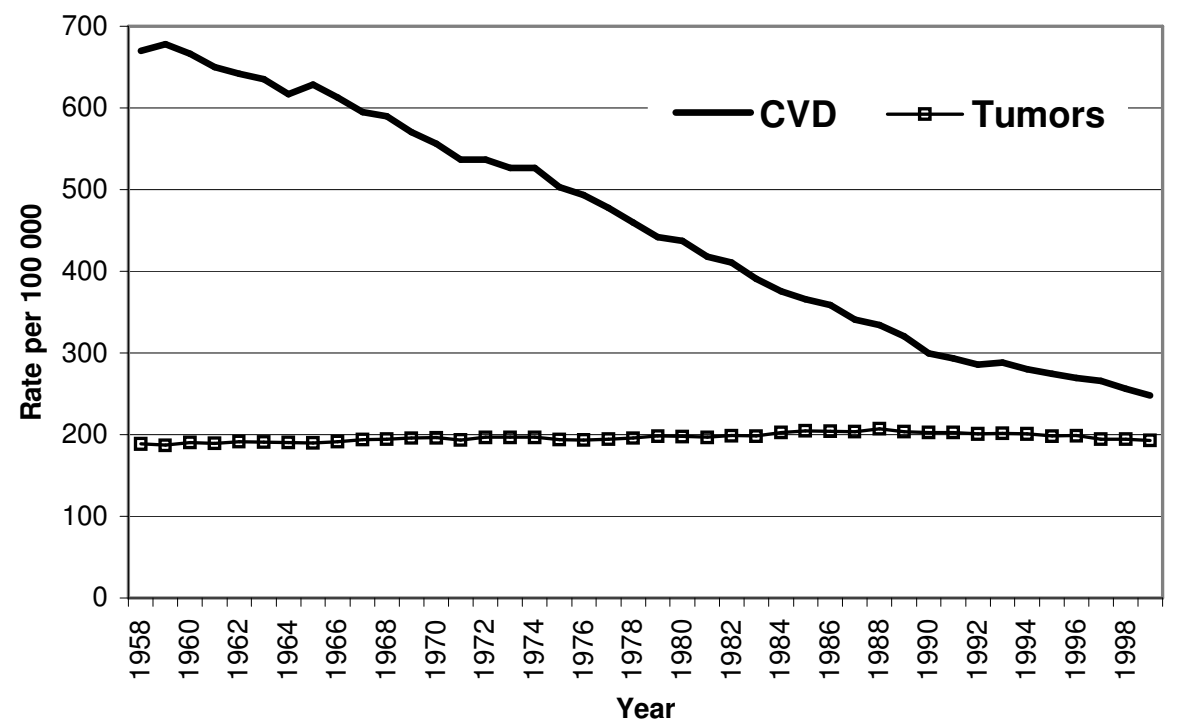

Sources : Deaths : Bureau fédéral de la statistique, 1958-1969. Statistique Canada, Catalogues 84-206 (1970-1986), 84-204 (19781986), 82-003S (1987-1989), 82-003S15 (1989-1990), 82-003S11 (1990), 84-208 (1991-1993), 84-211 (1991-1992), 84-210XPB (1993-1995), 84-208-XPB (1994-1995), 84-209-XPB (1995-1999), 84F0210XPB (1996-1997), 84F0208 (1996-1999), 84F0211XPB (1998-1999). Populations: Statistique Canada, Catalogues 91-512 (1921-1971), 91-518 (1971-1986), 91-210 (1987-1992), 91-213 (1993-1994), 91-213-XPB (1995-1999). 
Figure 5 reveals that violent and accidental mortality decreased considerably starting in the 1970s. The evolution of mortality by respiratory diseases was more irregular, but the general trend was a decline as well. By the end of the $20^{\text {th }}$ century, a Canadian was more likely to die from a respiratory disease than from an accident or a trauma, whereas these probabilities were more or less equal at the beginning of the period.

The standardized mortality rate from digestive system diseases fell steadily over the entire period. Moreover, mortality rate from diabetes first decreased in the 1970s, and then had a modest increase beginning in the 1990s. The emergence of AIDS had a surprising impact on standardized mortality rate by infectious and parasitic diseases (IPD). Between 1986 and 1991, the mortality rate from IPD doubled. It continued rising until 1995, then dropped substantially. Mortality rate from Alzheimer's disease soared, even though the standardized rate eliminates the aging effect of the population. The progress was quite astonishing: the rate was multiplied by nine in only twenty years 9 .

${ }^{9}$ This growth is biased by the fact that Alzheimer's disease was not introduced into the ICD until 1979, and by the fact that this disease has been a popular diagnosis among doctors needing to determine the initial cause of death (Vallin and Meslé 1996). 
Figure 5: Standardized mortality rates by traumas, respiratory diseases, digestive system diseases, infectious and parasitic diseases (IPD), diabetes and Alzheimer's disease, both sexes, Canada, 1958-1999

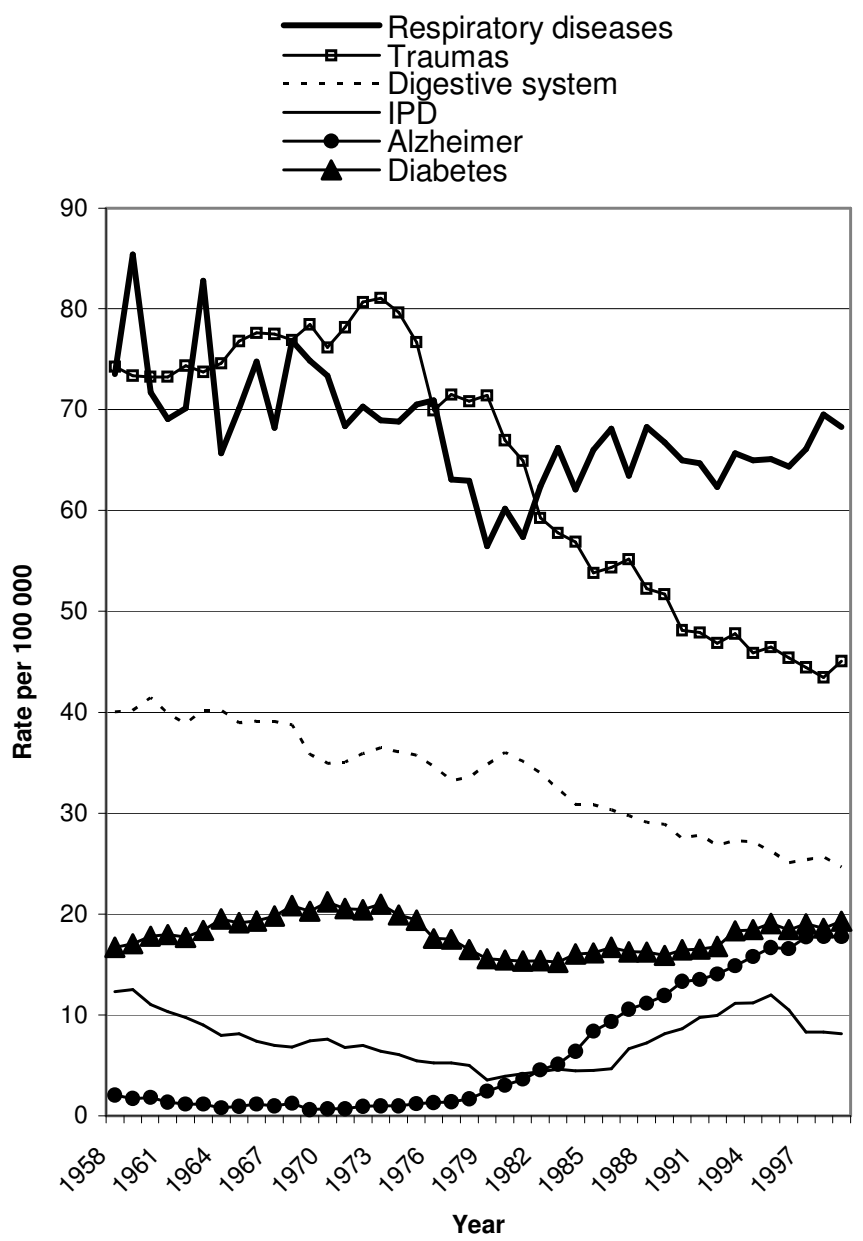

Sources: Same as figure 4. 


\subsubsection{Did specific changes occur within chronic diseases groups?}

When Olshansky and Ault suggested that the pattern of causes of death remained more or less unchanged between the third and fourth phases, they did not account for the possible variations occurring within groupings of causes of death. It was found that Olshansky and Ault's second hypothesis was not corroborated. We will go even further: not only did the pattern of large groups of causes of death not remain stable, but there were specific changes within these same large groups of causes of death. Three major groups of chronic causes of death were assessed: cardiovascular diseases, cancer and respiratory diseases.

Malignant tumours were studied according to the sex since men and women have different seats of cancer, and usually have a cancer pattern of their own. Four subcategories were created for men and five for women (figures 6 and 7). Cancer of the respiratory system among men increased significantly until the 1980s, after which their weight among tumours stabilized, then slightly decreased at the end of the last century. The growing importance of respiratory system tumours among men was counterbalanced by the decrease of cancer of the digestive system.

Women's mortality rates by cancer had similar transformations but, unlike men, their digestive system tumours remained dominant throughout the entire period despite an exceptional increase in the importance of respiratory system tumours starting in the early 1970s (figure 7). Moreover, the importance of genito-urinary cancers dropped by half between 1958 and 1999, that of breast cancer decreased by $3 \%$ and that of "other tumours" went from $18 \%$ to $23 \%$ of the total amount of tumours.

Even though the use of tobacco in Canada has seen a significant decrease between 1971 and 2005 , dropping from $49 \%$ to $19 \%$ for men and from $30 \%$ to $15 \%$ for women, the importance of respiratory tumours for both sexes can be explained by the fact that the onset of cancer occurs decades after exposure to carcinogenic agents. Therefore, the importance of respiratory tumours in the 1990s is directly related to the use of tobacco in the 1960s and 1970s (OECD 2007).

As for cardiovascular diseases, the only clear change between 1958 and 1999 proved to be the significant decrease of hypertensive diseases (not illustrated). The incidence of ischemic cardiopathies and of cerebro-vascular diseases within all CVD slightly declined, whereas that of "other diseases" grew considerably. 
Figure 6: Distribution of deaths by cancer according to the type of cancer, men, Canada, 1958-1999

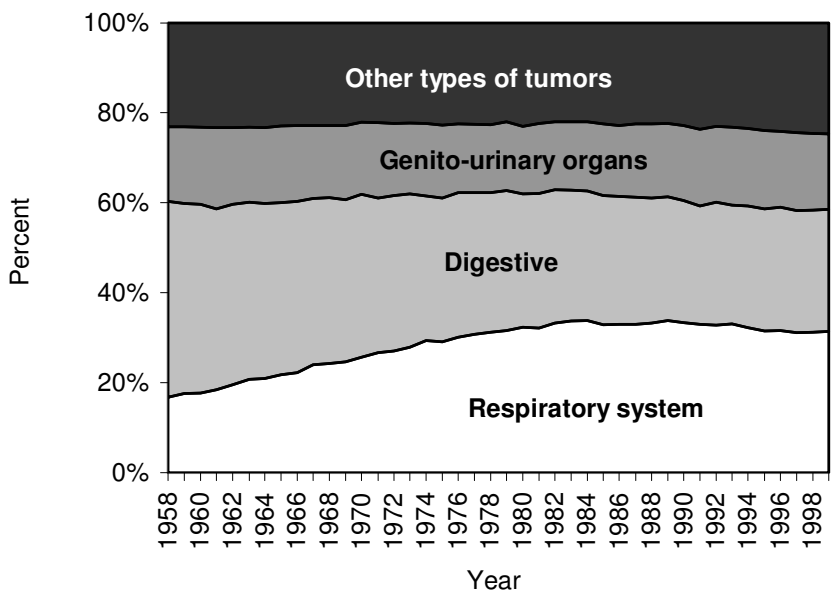

Sources: Same as figure 4.

Figure 7: Distribution of deaths by cancer according to the type of cancer, women, Canada, 1958-1999

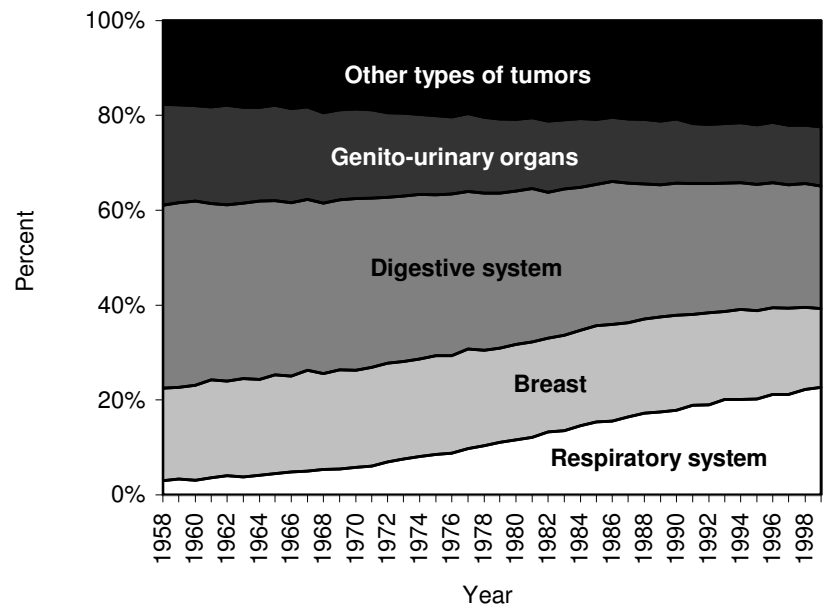


Sources: Same as figure 4

Diseases of the respiratory system were split into three groups (not illustrated): pneumonia and influenza; chronic obstructive pulmonary diseases (emphysema, asthma, chronic bronchitis); and other. The general trend was characterized by a steady decrease in the proportion of pneumonias and influenza and, in return, by an increase of chronic obstructive pulmonary diseases. The weight of the latter within the whole respiratory diseases group was constant during the last twenty years of the period and comprised about half of deaths.

\subsubsection{Did a gradual shift towards older ages take place in mortality by chronic diseases? (Olshansky and Ault 1986)}

Olshansky and Ault's last hypothesis consisted of a postponement of age at death by chronic diseases. According to them, this delay would neither be caused by a reduction of chronic diseases' incidence, nor by a deferment of age at which chronic diseases develop. This shift of age at death towards older ages, if it takes place, would be due to a prolonging of survival with chronic diseases; in other words to an expansion of morbidity.

Two indicators are used in order to bring to light the validity of this premise. The mean age at death by chronic diseases is used, calculated from standardized rates by age so that the aging of population bias is eliminated. The distribution of deaths by chronic diseases according to age is also examined.

\section{Mean age at death by chronic diseases}

Figure 8 shows that the mean age at death did increase fairly steadily for all chronic causes of death. Alzheimer's disease clearly stands out with an age at death far higher than any other cause of death throughout the entire period, even though the general trend was a declining slope in the first twenty years. In 1999, the mean age at death from Alzheimer's disease was nearly 85 years.

The most striking and continuous growth of age at death belongs undoubtedly to chronic obstructive pulmonary diseases (COPD). The age at death of individuals suffering from COPD increased by 8.5 years (from 70.2 to 78.7 years) over the study period. Cardiovascular diseases had the $2^{\text {nd }}$ highest increase in mean age at death, although the increase was only 2.5 years over 42 years. 
Figure 8: Mean age at death by chronic diseases, both sexes, Canada, 1958-1999 (calculated from age-specific standardized rates)

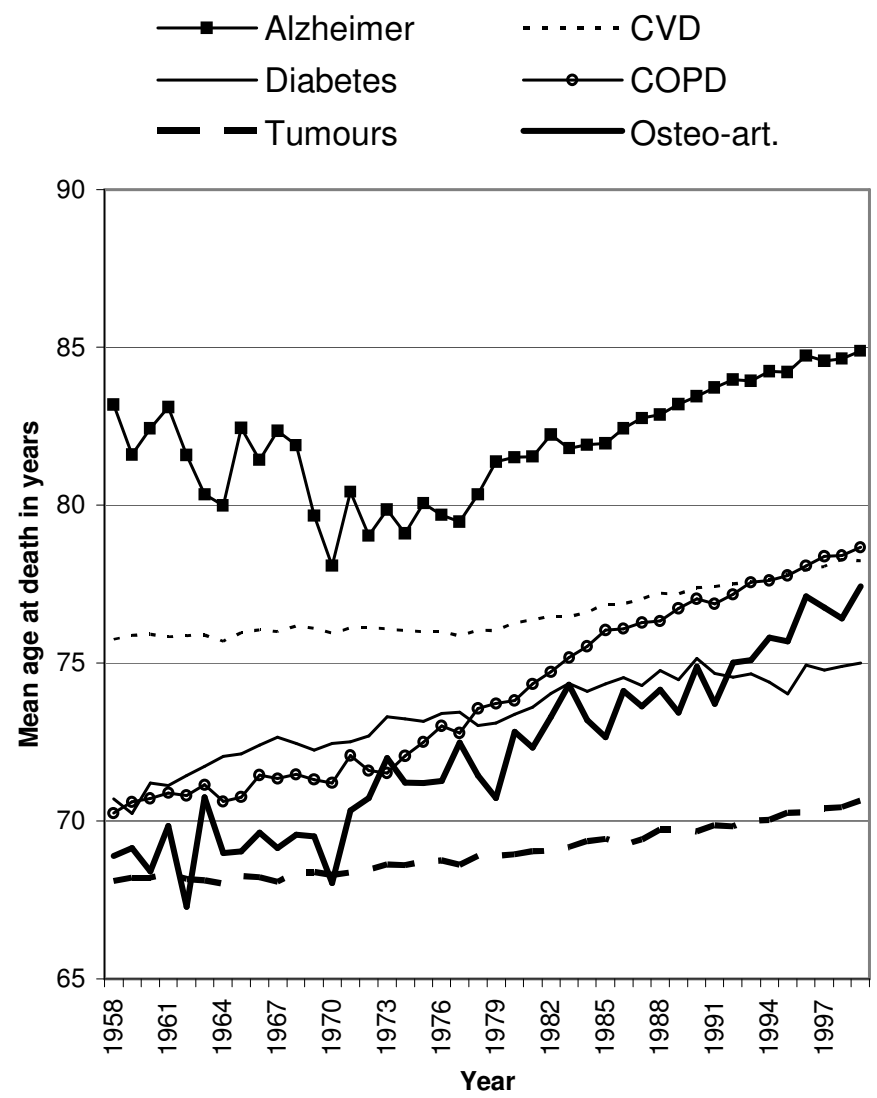

Sources: Same as figure 4.

Even though the evolution of the mean age at death from osteo-articular diseases was quite irregular, it grew significantly and, at 77.5 years in 1999, it was about average compared to the other chronic diseases. In addition, the mean age at death from diabetes was 75 years at the end of the period, which ranks that disease second to last. The growth of its mean age at death between 1958 and 1999 was 4.3 years, which is the average. 
Finally, the mean age at death by tumours trails at the bottom throughout the entire interval. The average age at death for an individual suffering from cancer only grew from 68.1 to 70.6 years from 1958 to 1999 .

\section{Distribution of deaths by chronic diseases according to age}

The deaths were distributed into three large age groups: 0-64 years, 65-84 years and 85 years and over. The proportion of standardized deaths by age groups was compared for each of the chronic disease groups (this is noted in each paragraphs below).

There were no major disruptions in the proportions of standardized deaths by age and by cardiovascular diseases over time, although there was a visible delay especially among people aged 85 years and over (not illustrated). In other words, individuals aged 85 years and older made up a greater proportion of total deaths by CVD at the end of the time span than at the beginning.

The age-specific portrayal of Canadians dying from malignant tumours is surprisingly invariable (not illustrated). The weight of deaths from people aged 65 years and less had the most notable change with a decrease of $7 \%$. Moreover, the Canadian population aged 85 years and over succumbed of cancer as much in 1999 as they did in 1958. This undermines the theory of the transition towards older ages of death by cancer.

As illustrated by figure 9, deaths by chronic obstructive pulmonary diseases are characterized by a switch of proportions between people aged less than 65 years and those aged 85 years and more during the interval. Therefore, the $85+$ age group supplanted the 0-64 age group as the second age category with the most deaths by COPD.

The evolving age distribution of deaths by diabetes, however, clearly indicates a transition of death at older ages. The proportion of deaths fell for both the 65-84 and the less than 65 years age groups. The $85+$ age group absorbed these numbers. 
Figure 9: Standardized age distribution of deaths by chronic obstructive pulmonary diseases (COPD), Canada, 1958-1999

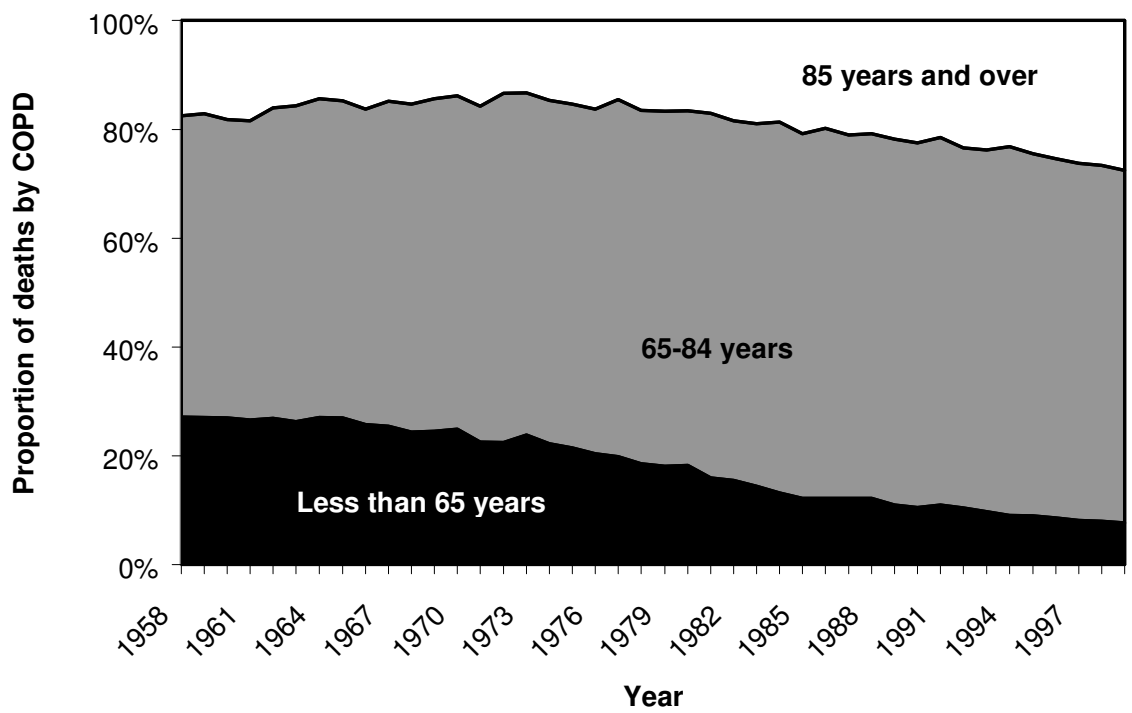

Sources: Same as figure 4.

Alzheimer's disease and osteo-articular, muscle and conjunctive tissue diseases most clearly reflect the transition to older ages at death. As with diabetes, the Alzheimer's age group 85+ was the only one that increased in proportion between 1958 and 1999. Alzheimer's disease is also the only chronic affliction where most deaths occur after 85 years old. As for diseases of the osteo-articular system, the weight of the age group $85+$ more than doubled (from $16 \%$ to $34 \%$ ) and the proportion of the youngest age group (0-64) tumbled from $30 \%$ to $16 \%$.

\subsubsection{Did mortality by social pathologies decline? (Rogers and Hackenberg 1987)}

In addition to Olshansky and Ault (1986), Rogers and Hackenberg (1987) also suggested a fourth stage of the epidemiologic transition. We examined their hypothesis that there would be a decrease of mortality by social pathologies. Social pathologies typically refer to mortality caused by accidents and homicides, and also to deaths 
caused by lifestyle, such as suicides, liver disease induced by alcoholism and lung disease brought on by tobacco use. For the purpose of this study, accidents, homicides and suicides were analyzed.

Figure 10 illustrates the evolution of standardized mortality rates for accidents, suicides and homicides. It suggests that accidental deaths clearly lead as the main cause of death from social pathologies throughout the entire period. All the same, mortality due to accidents started decreasing rapidly in the early 1970s. In the 1990s, it was still declining, but at a slower rate. Between 1973 and 1999, the accidental mortality rate was cut in half.

Figure 10: Standardized mortality rates by accidents, suicides and homicides, Canada, 1958-1999

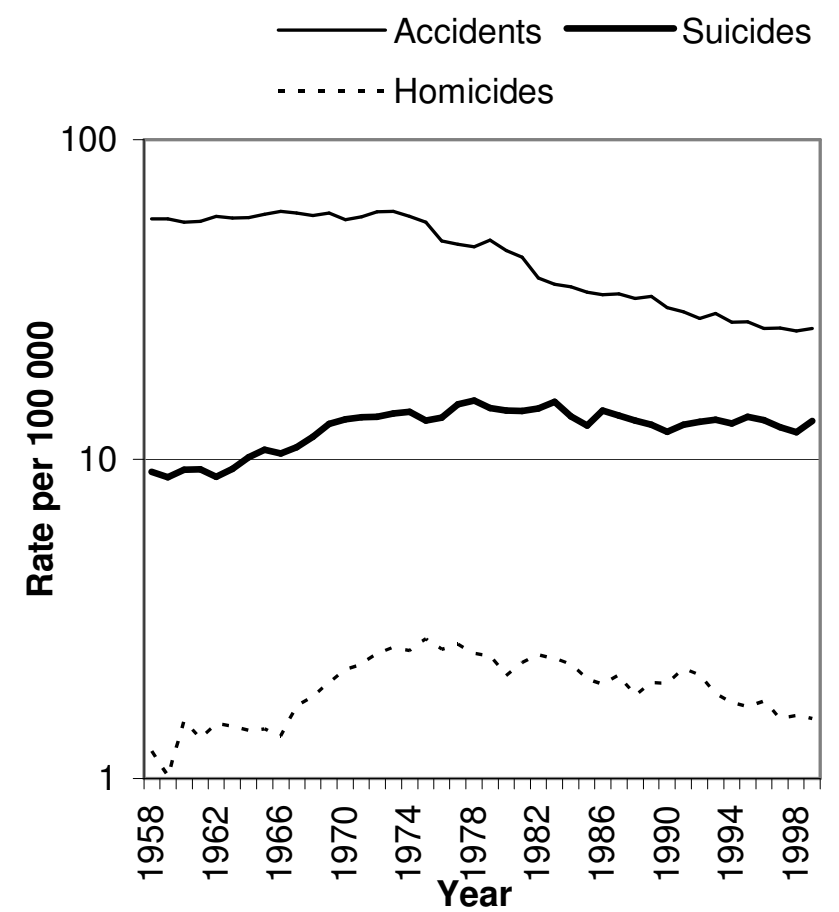

Sources: Same as figure 4. 
Mortality by suicide slightly increased over the entire interval. The growth of mortality by suicide was more impressive during the first half of the period. The pronounced decrease of mortality by accidents, combined with suicide rates that have been nearly unchanged since the 1980s, brings the two curves closer together. In 1958, the Canadian population had six times more risks of dying from an accident than from a suicide, but in 1999 the same ratio had dropped to two.

As for homicides, they are the least frequent social pathology during the whole period. Like mortality by accidents and by suicide, homicides have seen their standardized mortality increase as well in the 1970s. After reaching their culminating point at 2.6 deaths per 100000 in 1977, mortality by homicide declined slowly. At the end of the century, the standardized mortality rate by homicide was at the same level as it was at the end of the 1960s.

\subsubsection{Was the impact of AIDS on mortality significant? Did a resurgence of infectious diseases like cholera, diphtheria and dengue take place? (Omran 1998)}

In 1998, Omran also proposed a fourth stage, in addition to his three initial stages. It is characterized, among other things, by the emergence of new infectious diseases and by the reappearance of former infectious diseases. Although this fourth stage described by Omran was aimed mostly at developing countries, he also mentioned that developed countries should keep an eye on the evolution of AIDS, cholera, diphtheria and dengue. The impact of these four diseases in Canada since 1958 is examined.

There has not been a resurgence of cholera, diphtheria and dengue in Canada. The last death attributable to cholera in Canada goes back to 1959; two Canadians died from dengue between 1958 and 1999; and diphtheria caused a total of 95 deaths during the same period.

On the other hand, the surfacing of AIDS, which first attributable death occurred in 1983 in Canada, had a small repercussion on the overall Canadian mortality. The effect of the onset of AIDS on women's mortality was not significant, as the mortality rate by AIDS among females never reached 2 per 100000 . However, the impact of AIDS on male mortality was not trivial. After rising to 11 deaths per 100000 in 1995, men's mortality rates by AIDS started declining astoundingly and, in 1999, their mortality rate was a fifth of what it was in 1995 .

AIDS did not affect all age groups in the same way. For each age group, the proportions of deaths due to AIDS are illustrated by a Lexis surface (figure 11). The Lexis surface is a 3-dimension figure, with the dimensions being age (y axis), years ( $\mathrm{x}$ axis), and the degree of intensity of the trend (colors inside the graph). The colored scale represents the degrees of intensity, in this case, the mortality rates by AIDS. 
Unlike most other causes of death, the mortality due to AIDS is at its lowest among people aged 60 and over (no color on the graph means the deaths by AIDS among total deaths $=0 \%$ ). Individuals less than 20 years old are equally not affected. However, the impact of AIDS on adult mortality (20-49 years) is more severe, causing up to $16 \%$ of the total number of deaths among the age group 30-34 years in 1995 (20\% for men). This can be observed by the darkest colors (i.e. highest mortality) being aligned with ages 30 to 40 years old. But at the end of the century, the importance of AIDS as a cause of death among people aged 25-44 years was already fading.

\section{Figure 11: Proportion of deaths attributable to AIDS (in \%) according to the age group, both sexes, Canada, 1980-1999 ${ }^{10}$}

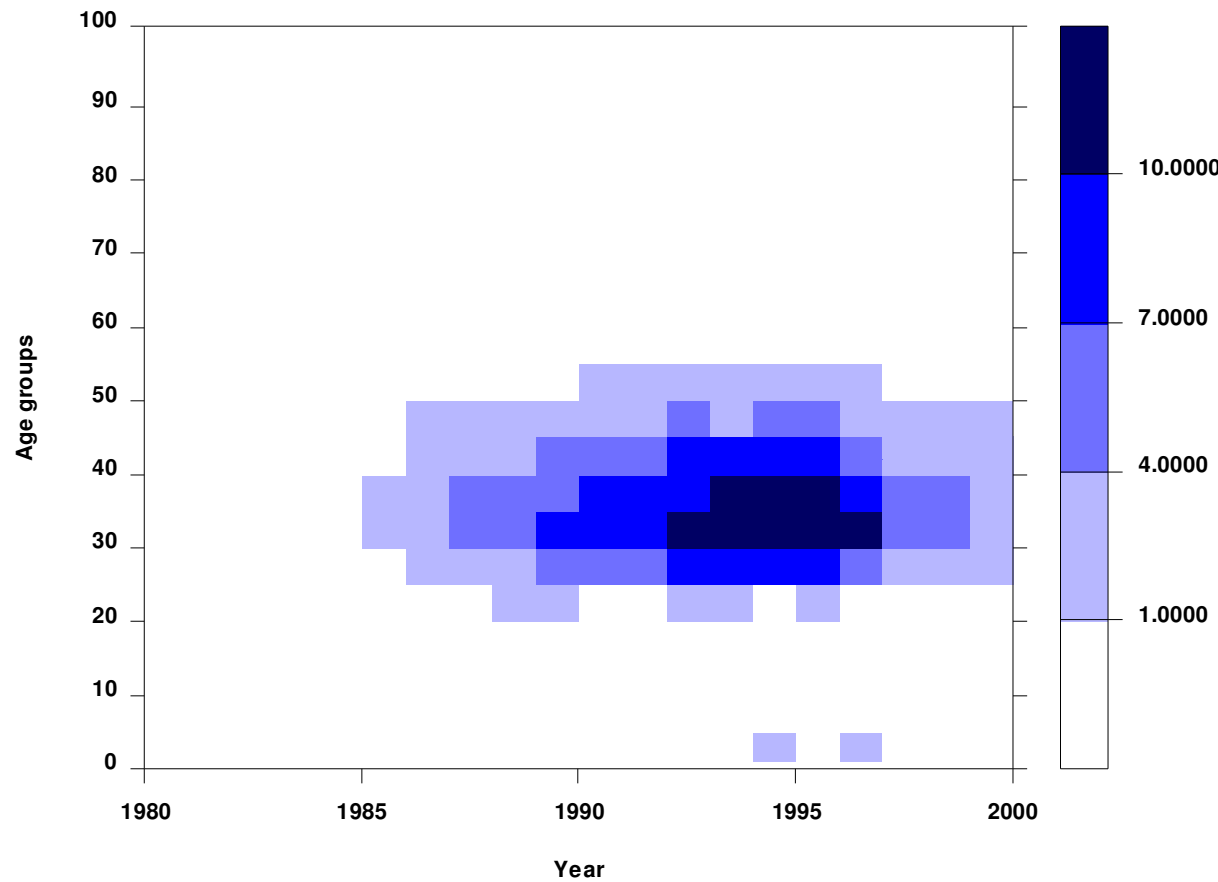

Sources: Statistique Canada, Catalogues 84-206 (1980-1986), 84-204 (1980-1986), 82-003S (1987-1989), 82-003S15 (1989-1990), 82-003S11 (1990), 84-208 (1991-1993), 84-211 (1991-1992), 84-210-XPB (1993-1995), 84-208-XPB (1994-1995), 84-209-XPB (1995-1999), 84F0210XPB (1996-1997), 84F0208 (1996-1999), 84F0211XPB (1998-1999).

${ }^{10}$ A Lexis figure helps visualize the trend in three dimensions: age groups, years or periods, and the level of intensity. The color scale circumscribes the levels of intensity of mortality. 


\subsubsection{Did mortality due to pneumonia and influenza increase? (Olshansky et al.} 1998)

In their suggestion of a fifth stage of the epidemiologic transition, Olshansky et al. (1998) claim that mortality due to pneumonia and influenza increases due to population aging. Figure 12 displays the standardized mortality rate by pneumonia and influenza according to sex since 1958. The figure reveals that mortality was subject to abrupt variations due to the epidemic nature of influenza and pneumonia, especially during the first half of the period. The standardized rate follows the same trend for both sexes, the only difference being the higher mortality of men compared to women. Overall, the general trend was a decline of mortality until the end of the 1970s. During the last twenty years of our study, mortality fluctuated slightly but became quite stable for both men and women.

Figure 12: Standardized mortality rates by pneumonia and influenza according to sex, Canada, 1958-1999

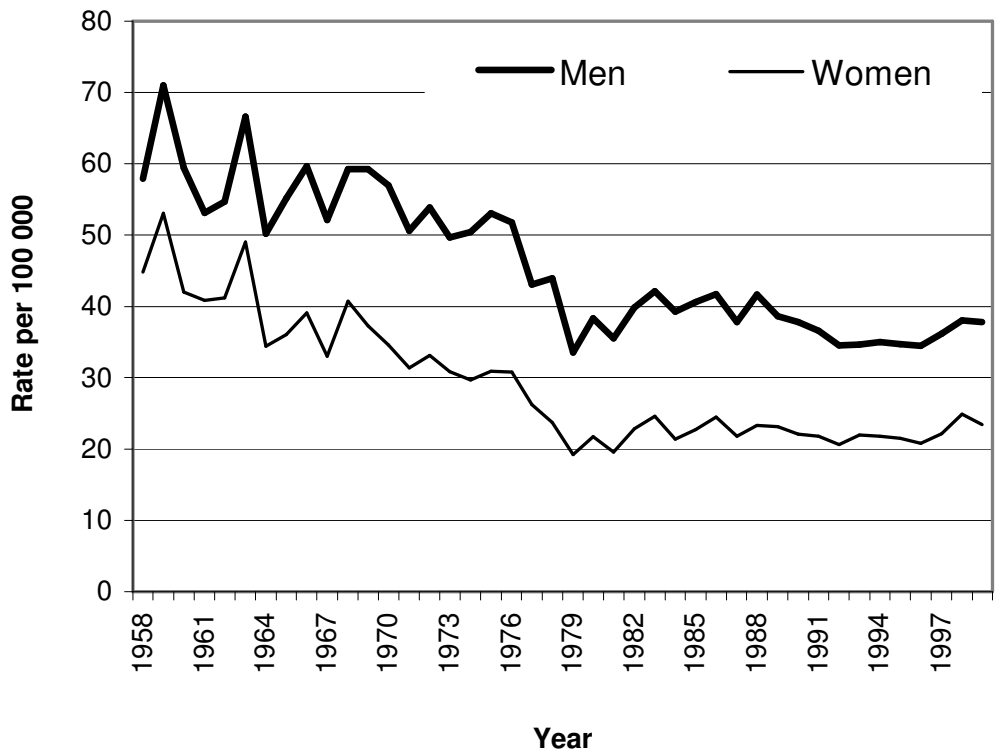

Sources: Same as figure 4. 


\section{Discussion}

In conclusion, distinct stages do not emerge from the empirical Canadian mortality data between 1958 and 1999 to support the epidemiologic transition. Many researchers have hypothesized on the matter, and some of their premises were refuted, others confirmed. A summary of the findings is below.

1. Was mortality's decline concentrated mostly in advanced ages and did the decline occur at nearly the same pace for males and females? (Olshansky and Ault 1986)

- Yes, older age groups (65 years and over) have gradually contributed more and more to the decline of Canadian mortality since 1958.

- $\quad$ No, the decline of mortality between 1958 and 1999 did not occur at the same pace for women and for men.

2. Did the pattern of mortality by cause become stable (Olshansky and Ault 1986)?

- No, standardized mortality rates did not evolve the same way among different causes. The proportion of deaths due to cardiovascular disease had historically dominated the spectrum. But over the past 50 years, that proportion has fallen while deaths due to tumours have grown.

\section{Did specific changes occur within chronic disease groups?}

- Yes, and the major modification was the transfer of predominance from digestive system tumours to respiratory system tumours. 
4. Did a gradual shift towards older ages take place in mortality by chronic diseases? (Olshansky and Ault 1986)

- Yes, particularly for chronic obstructive pulmonary diseases and for diseases of the osteo-articular, muscular and conjunctive tissue system. However, the postponement towards older ages of death by cancer did not prove to be significant.

5. Have we observed a decline of mortality by social pathologies, more precisely homicides, suicides and accidents? (Rogers and Hackenberg 1987)

- Yes, especially since the middle of the 1970s.

6. Was the impact of AIDS on mortality significant? Did a resurgence of infectious diseases like cholera, diphtheria and dengue take place? (Omran 1998)

- $\quad$ No, the impact of AIDS on mortality lasted only a few years and was limited to men aged 20-49 years old.

- No, there was no resurgence of infectious diseases like cholera, diphtheria and dengue.

7. Did mortality due to pneumonia and influenza increase? (Olshansky et al. 1998)

- $\quad$ No. Mortality due to pneumonia and influenza decreased between 1958 and 1980, and then stabilized until the end of the century. 
Robine (2001) as well as Meslé and Vallin (2002, 2004, 2005) studied the theory of the epidemiologic transition, but their observations were not examined in this research paper. It would have been interesting to look at Robine's redefinition of the third stage, called the "age of the conquest of the extent of life". According to him, deaths are indeed postponed to older ages, but this would not imply a reduction in the dispersion of life spans. As for Meslé and Vallin (2002), their response to the traditional epidemiologic transition is a "sanitary transition" comprised of two stages only. They identify the second stage as the "cardiovascular revolution", which is portrayed by a continuation of improvement in survival mostly imputable to the decline of cardiovascular diseases. This hypothesis by Meslé and Vallin is easily observable for Canada, as can be seen on figure 13. The prolongation of mortality's decrease between 1958 and 1999 was almost entirely due to the decline of mortality by cardiovascular diseases.

Although Meslé and Vallin's broader redefinition of a health transition (including a cardiovascular revolution as the second stage and a possible third stage described as a slowing down of ageing) seems the most adequate proposition, it does not account for the evolution of every major group of death causes. 
Figure 13: Standardized mortality rates for all deaths, for deaths by cardiovascular diseases, and for deaths by all other causes, Canada, 1958-1999

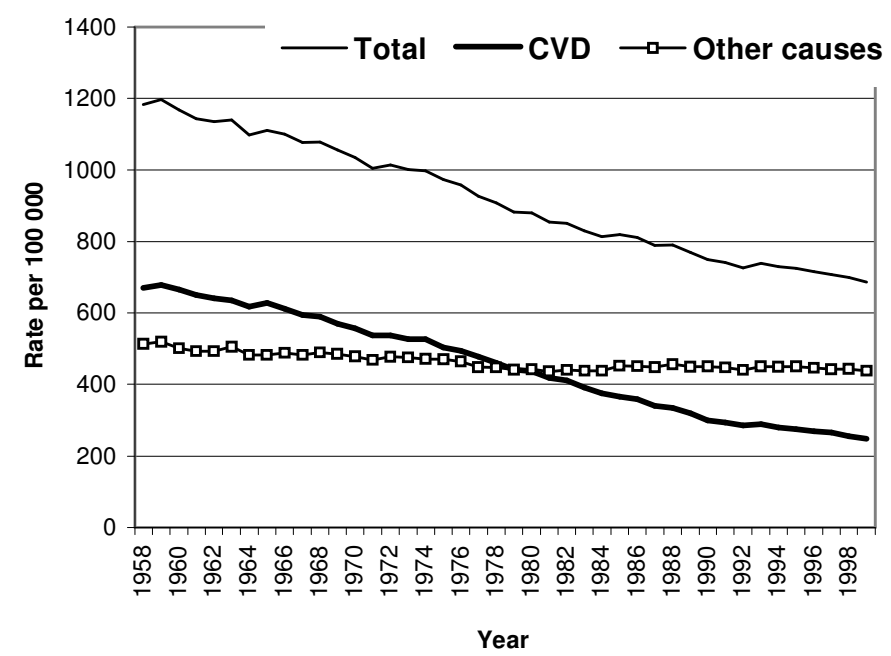

Sources: Same as figure 4.

\section{Conclusion}

We conclude, first, that the evolution of mortality and of the pattern of causes of death in Canada do not genuinely fit the theory of the epidemiologic transition and, second, that the fragmentation of the theory of the epidemiologic transition into distinctive stages delimited in time proves to be inappropriate for Canada, at least since the middle of the last century. Rather, the epidemiologic transition of the last fifty years in Canada should be perceived as a continuum of the third stage during which mortality continues to decrease and during which chronic diseases are largely predominant. More precisely, the decline of mortality increasingly profited the elderly; the proportion of deaths by malignant tumours grew while cardiovascular mortality decreased significantly; the importance of respiratory system deaths (lung, bronchial tubes and windpipe cancer as well as chronic obstructive pulmonary diseases), has been growing as a result of tobacco consumption; finally, infectious and parasitic diseases have subsisted, although their potential threat has been modest thus far. 


\section{Acknowledgements}

An earlier version of this paper was presented at the XXV IUSSP International Population Conference, Tours, France, July 2005. We are grateful to Ramana Zanfongnon for her valuable assistance in the preparation of data and to Beth Martin for reviewing the proper use of English. This research was supported by a grant from the Social Sciences and Humanities Research Council of Canada (410-2003-0687). 


\section{References}

Arriaga, E. (1984). Measuring and Explaining the Change in Life Expectancies. Demography 21: 83-96.

Bah, S.M. and Rajulton, F. (1991). Has Canadian mortality entered the fourth stage of the epidemiologic transition?. Canadian Studies in Population 18(2): 18-41.

Bourbeau, R. and Smuga, M. (2003). La baisse de la mortalité: les bénéfices de la médecine et du développement. In: Piché, V. and Le Bourdais, C. (eds.) La démographie québécoise, Enjeux du XXI siècle. Montréal: Les Presses de l'Université de Montréal: 24-65.

Brownson, R.C., Remington, P.L. and Davis, J.R. (1993). Chronic Disease Epidemiology and Control. American Public Health Association. Washington, $358 \mathrm{p}$.

Bureau fédéral de la statistique (1948-1949). Statistiques vitales. Division de la santé et du bien-être, section des statistiques vitales. Canada. Ottawa.

Bureau fédéral de la statistique (1951-1969). Statistique de l'état civil. Division de la santé et du bien-être, section de l'état civil. Canada. Ottawa.

Burgio, A. and Frova, L. (1995). Projections de mortalité par cause de décès. Population 50: 1031-1052.

Canadian Human Mortality Database (CHMD). (2004). Université de Montréal, Département de démographie, (pages accessed May 22, 2008) http://www.bdlc. umontreal.ca/CHMD/index.htm.

Caselli, G. and Egidi, V. (1991). New Frontiers in Survival: the Length and Quality of Life. Luxembourg: Eurostat, 1991. Presentation at the international conference "Human Resources in Europe at the dawn of the $21^{\text {st }}$ century".

Center for Disease Control and Prevention. (2007). Chronic Disease Prevention. National Center for Chronic Diseases Prevention and Health Promotion, (page accessed on May 22, 2008) http://www.cdc.gov/nccdphp.

Chasteland, J-C. and Chesnais, J-C. (1997). La population du monde: enjeux et problèmes. Travaux et Documents, Cahier 139. Paris: PUF, INED: 630 p. 
Chui, T., Tran, K. and Maheux, H. (2006). Immigration au Canada: un portrait de la population née à l'étranger, Recensement de 2006: résultats. Statistique Canada, Division de la statistique sociale et autochtone.

Dominion Bureau of Statistics (1921-1947). Vital Statistics. Canada. Ottawa.

Fetter, B. (1997). The Epidemiologic Transition: One, Many or None?. Health Transition Review 7(2): 235-237.

Mackenbach, J.P. (1994). The Epidemiologic Transition Theory. Journal of Epidemiology and Community Health. 48: 329-331.

Meslé, F. (1997). L'évolution de la mortalité par cause: les différentes facettes de la transition épidémiologique. Médecine / Sciences 13(8-9): 1008-1017.

Meslé F. and Vallin, J. (2002). La transition sanitaire: Tendances et perspectives in Caselli, G., Vallin, J., and Wunsch, G. Démographie: Analyse et Synthèse, vol III - Les déterminants de la mortalité. INED: 439-461.

Ministère de la Santé et des Services Sociaux du Québec. (2005). Programme National de Santé Publique 2003-2012. (page accessed May 21, 2008). http://msssa4.msss.gouv.qc.ca/fr/document/publication.nsf/fb143c75e0c27b6985 2566aa0064b01c/67b76aa5887e7a9685256efd006c9013?OpenDocument\&Highl ight $=0$,Programme.

Nagnur, D. and Nagrodski, M. (1990). Epidemiologic transition in the context of demographic change: The Evolution of Canadian Mortality Patterns. Canadian Studies in Population 17(1): 1-24.

Nagnur, D. and Nagrodski, M. (1987). Cause-deleted Life Tables for Canada 19211981: An Approach Towards Analyzing Epidemiological Transition. Ottawa: Statistics Canada.

Organisation for Economic Co-operation and Development (2007). OECD Health Data 2007 - Frequently Requested Data. (page accessed May 21, 2008). http://www.oecd.org/document/16/0,3343,fr_2649_201185_2085200_1_1_1_1,0 $0 . \mathrm{html}$

Olshansky, S.J. and Ault, A.B. (1986). The fourth stage of the epidemiologic transition: The age of Delayed Degenerative Diseases. The Milbank Quarterly 64(3): 355391. 
Olshansky, S.J., Carnes, B.A., Rogers, R.G. and Smith L. (1998). Emerging Infectious Diseases: the Fifth Stage of the Epidemiologic Transition? World Health Statistics Quarterly 51(2-3-4): 207-217.

Omran, A.R. (1998). The Epidemiologic Transition Theory Revisited Thirty Years Later. World Health Statistics Quarterly 51: 99-119.

Omran, A.R. (1971). The Epidemiologic Transition: A Theory of the Epidemiology of Population Change. Milbank Memorial Fund Quarterly 49(4): 509-538.

Robine, J-M. (2001). Redéfinir les phases de la transition épidémiologique à travers l'étude de la dispersion des durées de vie. Population 56(1-2): 199-222.

Rogers, R.G. and Hackenberg, R. (1987). Extending epidemiologic transition theory: A new stage. Social Biology 34(3-4): 234-243.

Rogers, J. and Nelson, M.C. (1997). The Epidemiologic Transition Revisited: or What Happens If We Look Beneath the Surface?. Health Transition Review 7(2): 241255.

Santé Canada (2004). Surveillance des maladies chroniques majeures en direct. Direction générale de la santé de la population et de la santé publique (DGSPSP) (page accessed May 21 2008), http://dsol-smed.hc-sc.gc.ca/dsol-smed/mcdsmcm/d_dis_f.html.

Statistique Canada (1973). Population 1921-1971: Révision des estimations annuelles de la population par sexe et par groupe d'âge, Canada et provinces. Direction du recensement, section des estimations et des projections démographiques, Catalogue 91-512. Ottawa.

Statistique Canada (1970-1974). La statistique de l'état civil, Volume III - Décès. Division de la santé, Section de l'état civil, Catalogue 84-206. Ottawa.

Statistique Canada (1975-1977). La statistique de l'état civil, Volume III - Décès. Division de la santé, Section de la statistique de l'état civil et des registres des Maladies, Catalogue 84-206. Ottawa.

Statistique Canada (1978-1983). La statistique de l'état civil, Volume I - Naissances et décès. Division de la santé, Section de la statistique de l'état civil et des registres de maladies, Catalogue 84-204. Ottawa. 
Statistique Canada (1979). Population: Révision des estimations annuelles de la population selon le sexe l'âge, Canada et provinces, 1971-1976. Secteur du recensement et des enquêtes ménages, Division des estimations et des projections démographiques, Catalogue 91-518. Ottawa.

Statistique Canada (1983). Population: Estimations intercensitaires annuelles de la population selon le sexe l'âge, Canada et provinces, 1976-1981. Division de la démographie, section des estimations démographiques. Catalogue 91-518. Ottawa.

Statistique Canada (1978-1983). La statistique de l'état civil, Volume III - Mortalité, liste sommaire des causes. Division de la santé, Section de la statistique de l'état civil et des registres de maladies, Catalogue 84-206. Ottawa.

Statistique Canada (1984). La statistique de l'état civil, Volume IV - Causes de décès. Division de la santé Section de la statistique de l'état civil et de la santé. 1984, Catalogue 84-203. Ottawa.

Statistique Canada (1984-1986). La statistique de l'état civil, Volume I - Naissances et décès. Division de la santé, Section de la statistique de l'état civil et de la santé, Catalogue 84-204. Ottawa.

Statistique Canada (1984-1986). La statistique de l'état civil, Volume III - Mortalité, liste sommaire des causes. Division de la santé, Section de la statistique de l'état civil et de la santé, Catalogue 84-206. Ottawa.

Statistique Canada (1987-1988). Rapports sur la santé - Décès. Centre canadien d'information sur la santé, Supplément no 15, 2, 1, Catalogue 82-003S. Ottawa.

Statistique Canada (1987-1989). Rapports sur la santé - Mortalité, liste sommaire des causes. Centre canadien d'information sur la santé, Supplément no 12, 1, 1, Catalogue 82-003S. Ottawa.

Statistique Canada (1989). Rapports sur la santé - Décès. Centre canadien d'information sur la santé, Supplément no 15, 3, 1, Catalogue 82-003S15. Ottawa.

Statistique Canada (1990). Rapports sur la santé - Causes de décès. Centre canadien d'information sur la santé, Supplément no 11, 4, 1, Catalogue 82-003S11. Ottawa. 
Statistique Canada (1990). Rapports sur la santé - Décès. Centre canadien d'information sur la santé, Supplément no 15, 4, 1, Catalogue 82-003S15. Ottawa.

Statistique Canada (1991). Causes de décès. Centre canadien d'information sur la santé, Catalogue 84-208. Ottawa.

Statistique Canada (1991). Décès. Centre canadien d'information sur la santé, Catalogue 84-211. Ottawa.

Statistique Canada (1992). Estimations annuelles postcensitaires de la population suivant l'état matrimonial, l'âge, le sexe et composantes de l'accroissement, Canada, provinces et territoires, au $1^{\text {er }}$ juin 1987, 1988, 1989, 1990, 1991, 1992. Division de la démographie, section des estimations démographiques, Catalogue 91-210. Ottawa.

Statistique Canada (1992-1993). Causes de décès. Division des statistiques sur la santé, Catalogue 84-208. Ottawa.

Statistique Canada (1992). Décès. Division des statistiques sur la santé, Catalogue 84211. 1992. Ottawa.

Statistique Canada (1993-1994). Statistiques démographiques annuelles. Division de la démographie, Catalogue 91-213. Ottawa.

Statistique Canada (1993-1995). Naissances et décès. Division des statistiques sur la santé, Catalogue 84-210-XPB. Ottawa.

Statistique Canada (1994-1995). Causes de décès. Division des statistiques sur la santé, Catalogue 84-208-XPB. Ottawa.

Statistique Canada (1995-1999). Mortalité - Liste sommaire des causes. Division des statistiques sur la santé, Catalogue 84-209-XPB. Ottawa.

Statistique Canada (1996-1997). Naissances et décès. Division des statistiques sur la santé, Catalogue 84F0210XPB. Ottawa.

Statistique Canada (1996-1999). Causes de décès. Division des statistiques sur la santé, Item 84F0208. Ottawa.

Statistique Canada (1998-1999). Décès. Division des statistiques de la santé, Catalogue 84F0211XPB. Ottawa. 
Statistique Canada (1995-1999). Statistiques démographiques annuelles. Division de la démographie, Catalogue 91-213-XPB. Ottawa.

Statistique Canada (2002). Rapport sur l'état de la population du Canada 2001. Division de la démographie, Catalogue 91-209F. Ottawa.

Trowell, H.C. and Burkitt, D.P. (1981). Western Diseases: Their Emergence and Prevention. Cambridge, Massachusetts: Harvard University Press. 445 p.

Vallin, J. and Meslé, F. (2005). Convergence and divergence: An analytic framework of national and sub-national trends in life expectancy. Genus, Special issue on Increasing Longevity: Causes, Trends and Prospects, LXI (1): 83-124.

Vallin, J. and Meslé, F. (2004). Convergences and divergences in mortality. A new approach to health transition. Demographic Research, Special Collection 2: Determinants of Diverging Trends in Mortality, Article 2, 12-43. http://www.demographic-research.org/special/2/2.

Vallin, J. and Meslé, F. (1996). Comment suivre l'évolution de la mortalité par cause malgré les discontinuités de la statistique? Le cas de la France de 1925 à 1993. Dossiers et Recherches, INED, 53.

Vallin, J. and Meslé, F. (1987). Les causes de décès en France de 1925 à 1978 : reclassement selon la $8^{\mathrm{e}}$ révision de la Classification internationale. 1. Correspondance entre les $7^{\mathrm{e}}$ et la $8^{\mathrm{e}}$ revisions. Travaux et Documents, Cahier 115, Annexe IV, PUF, INED : 404 p.

Wolleswinkel-Van Den Bosch, J.H., Van Poppel, F.W.A and Mackenbach, J.P. (1996). Reclassifying Causes of Death to Study the Epidemiological Transition in the Netherlands, 1875-1992. European Journal of Population, 12: 327-361. 